Saint Louis University School of Law

Scholarship Commons

All Faculty Scholarship

2018

Accessibility of Medical Diagnostic Equipment - Implications for People with Disability

Lisa lezzoni

Elizabeth Pendo

Follow this and additional works at: https://scholarship.law.slu.edu/faculty

Part of the Disability Law Commons, and the Health Law and Policy Commons 


\title{
Accessibility of Medical Diagnostic Equipment - Implications for People with Disability
}

New England Journal of Medicine, Vol. 378. pp. 1371-1373 (April 12, 2018)

\section{Lisa Iezzoni}

Harvard University - Medical School

Elizabeth Pendo

Saint Louis University - School of Law

Date Written: April 12, 2018

\begin{abstract}
Under Attorney General Jeff Sessions, the U.S. Department of Justice (DOJ) has inactivated or rescinded numerous rules and guidelines issued by prior administrations, sometimes attracting considerable public attention in the process. Little noticed, however, was a decision by the DOJ on December 26, 2017, to formally withdraw four Advance Notices of Proposed Rulemaking related to Titles II and III of the Americans with Disabilities Act (ADA), including rulemaking that addressed making medical diagnostic equipment accessible to people with disability. For now, this step halts efforts on a national level to ensure accessibility of such equipment, which includes exam tables, weight scales, mammography equipment, and other diagnostic imaging technologies. It also forestalls explicit guidance for providers on what constitutes accessible medical diagnostic equipment and perpetuates existing confusion about this issue at many health care facilities. As we approach 30 years since the passage of the ADA in 1990, the absence of a clear federal rule in this area raises questions about how to improve access to medical diagnostic equipment for millions of Americans with disability, many of whom face considerable difficulty getting care because of inaccessible equipment in public and private health care settings.
\end{abstract}

Keywords: Disability, Americans with Disabilities Act, Medical Diagnostic Equipment, Health Regulation, Health Access, Health Disparities, Affordable Care Act, Promoting Wellness for Individuals with Disabilities Act

\section{Suggested Citation:}

Iezzoni, Lisa and Pendo, Elizabeth, Accessibility of Medical Diagnostic Equipment Implications for People with Disability (April 12, 2018). New England Journal of Medicine, Vol. 378. pp. 1371-1373 (April 12, 2018). 